\title{
Apontamentos sobre o estilo historiográfico de Arthur Cézar Ferreira Reis na obra A Amazônia e a cobiça internacional (edição de 1982) ${ }^{1}$
}

\author{
Notes on Arthur Cezar Ferreira Reis's historiographical style in \\ his work "A Amazônia e a Cobiça Internacional” (1982 edition)
}

\section{Alexandre Pacheco*}

\begin{abstract}
Resumo
A representação de portugueses, luso-brasileiros e brasileiros na obra A Amazônia e a cobiça internacional evidenciou o objetivo do historiador Arthur Cézar Ferreira Reis em demonstrá-los como heroicos defensores da Amazônia entre os séculos XVII e XX. Essa representação, que se calcou metaforicamente na luta das "forças da virtude" (representadas por portugueses, luso-brasileiros e brasileiros) contra as "forças usurpadoras" (representadas, sobretudo, pelos povos anglo-saxões), foi desenhada a partir de uma perspectiva não dialética, já que os estrangeiros jamais foram definitivamente demovidos de seus interesses de conquista da Amazônia. Essa representação deveria, a partir do "extremado sentimento" de nacionalidade de Arthur Reis, fazer que os grandes homens que estiveram a serviço da defesa da Amazônia fossem vistos como os mais aptos em estabelecer simbiose com o meio e com o elemento humano presente na região. Tal fato deveria servir
\end{abstract}

1 Neste texto, optou-se pela utilização da quinta edição da obra A Amazônia e a cobiça internacional, publicada em 1982 pela Editora Civilização Brasileira/Suframa, por reunir todos os prefácios das edições anteriores, que não só reafirmam o nacionalismo acendrado do autor sobre a problemática em tela, mas também ajudam a perceber o percurso da obra sobre o que o autor entendeu ser a crescente "consciência brasileira" a respeito da Amazônia, sobretudo entre os anos 1960 e 1980. Nesta edição, o autor optou por acrescentar alguns tópicos ao que se convencionou como o último capítulo das obras anteriores, intitulado "A pressão dos interesses universais". Acrescentou também algumas notas de rodapé nos capítulos relativos à Amazônia pós-colonial e um capítulo no final do livro, intitulado "O pacto amazônico". Fazem parte desta edição os seguintes capítulos em sequência: "Mundo tropical e empório de matérias-primas"; "Ingleses, irlandeses e holandeses tentaram a primeira surtida"; "Portugueses e espanhóis disputam o domínio"; "Os franceses participam da aventura"; "Os ingleses sugerem a secessão"; "A navegação do Amazonas"; "Expedições científicas escondiam propósitos"; "Os franceses pretendem o Amapá"; "Os ingleses penetram no Rio Branco"; "Viajantes e sugestões separatistas"; "O "bolivian syndicate' e o caso do Acre"; "A que vinha a expedição inglesa"; "O episódio da Hiléia”; "A pressão dos interesses universais" e "O pacto amazônico".

* Doutor em sociologia pela Universidade Estadual Paulista. Este trabalho vincula-se ao projeto de pesquisa intitulado "Arthur Reis: história, literatura e poder (década de 1960)", desenvolvido junto ao Centro de Estudos do Imaginário (CEI) da UNIR. E-mail: nelsonfonseca4@hotmail.com 
como exemplo de patriotismo tanto para seus leitores quanto para as ações dos homens que desejassem defender a Amazônia nos anos 1960.

Palavras-chave: Amazônia, colonização, miscigenação, processo de defesa, nacionalismo.

\begin{abstract}
:
The representation of the Portuguese, the Portuguese-Brazilians and the Brazilian people in A Amazônia e cobiça internacional showed what the historian Arthur Cezar Ferreira Reis intended by portraying them as heroic defenders of the Amazon between the $17^{\text {th }}$ and the $18^{\text {th }}$ centuries. This representation, metaphorically based in the fight between the "forces of virtue" (represented by the Portuguese, the Portuguese-Brazilian and the Brazilian people) against the "usurper forces" (represented mainly by the Anglo-Saxon people), was drawn from a non-dialectical perspective, since foreigners were never definitively diverted from their objective to conquer the Amazon. This representation should, by the perspective of Arthur Reis' idea of "extreme nationality", make the great men who were in the service of the defense of the Amazon to be seen as the most capable to establish a symbiosis with the environment and the human element present in the region. This fact should serve as an example of patriotism for both his readers and to actions of men who wished to defend the Amazon in the sixties.
\end{abstract}

Keywords: Amazon, colonization, miscegenation, defense process, nationalism.

A modernização capitalista na Amazônia se deu a partir de vários avanços e retrocessos que puderam ser verificados, sobretudo, no transcurso da inserção nacional e internacional da economia da borracha nos séculos XIX e XX. Problemas relativos a uma dependência dos investimentos estrangeiros e de mercados externos - e outros fatores responsáveis pela decadência econômica da região, como a resistência das elites locais em promover a produção da borracha em "bases mais capitalistas", e a inação do Estado em intervir nesse processo de modernização - não devem ser menos considerados. $^{2}$

Na última metade do século XX, porém, após um período de recomposição da economia da borracha nos anos 1940, em que as elites locais não se prepararam para enfrentar as fragilidades de uma economia de exportação frente ao mercado internacional, a decadência novamente se fez presente. A

2 WEINSTEIN, Barbara. A borracha na Amazônia: expansão e decadência, 1850-1920. São Paulo: Hucitec/ Edusp, 1993. p. 15-18. 
partir dos anos 1950 e, sobretudo, dos anos 1960, o Estado brasileiro, percebendo as dificuldades históricas dessa região em se integrar em bases mais sólidas ao restante da economia nacional, lançou mão de uma série de instrumentos de intervenção. Dentre eles, podem-se destacar a Superintendência do Plano de Valorização Econômica da Amazônia (SPVEA) ${ }^{3}$, a Superintendência do Desenvolvimento da Amazônia (SUDAM), o Banco da Amazônia (BASA) e a Superintendência da Zona Franca de Manaus. ${ }^{4}$

Dessa forma, ao contrário da economia extrativista que se desenvolveu na região e que permitiu espasmos de desenvolvimento econômico, a intervenção do Estado brasileiro a partir das décadas de 1950 e 1960 fez que o capitalismo avançasse de forma menos ininterrupta na região. Concomitantemente a esse movimento de intervenção, os anseios das elites locais por um processo de redenção da economia regional podem ser verificados, por exemplo, em projetos como o da criação no Amazonas, nos anos 1950, de um porto franco em Manaus - projeto que sofreu várias alterações até se transformar, em 1957, na Zona Franca de Manaus, a qual só se efetivou em $1967 .^{5}$

Nesse contexto de expectativas, entretanto, surgiram figuras como Arthur Cézar Ferreira Reis ${ }^{6}$ e Leandro Tocantins, intelectuais que influenciaram o destino da Amazônia ao se tornaram homens públicos à frente de órgãos como a SPVEA e o governo do estado do Amazonas nos anos 1950 e 1960. Com seus estudos, lançaram as bases dos problemas históricos que sempre impediram a integração da Amazônia às regiões mais desenvolvidas do país e do mundo, representando pelo menos parte dos anseios e inte-

3 Órgão federal que se pautou por ações nacionalistas até o ano de 1966. Foram ações voltadas não só à integração econômica da região, com um aproveitamento maior de seus recursos naturais, sobretudo pela associação entre o capital estatal e o privado nacional e pela valorização de aspectos de suas particularidades sociais e até culturais. (CARDOSO, Fernando Henrique; MÜLLER, Geraldo. Amazônia: expansão do capitalismo. São Paulo: Brasiliense, 1978. p. 109-115.)

4 IANNI, Otávio. Ditadura e agricultura: o desenvolvimento do capitalismo na Amazônia, 1964-1978. Rio de Janeiro: Civilização Brasileira, 1979. p. 55-62.

5 SERÁFICO, José; SERÁFICO, Marcelo. “A Zona Franca de Manaus e o capitalismo no Brasil” In: Estudos avançados, São Paulo, Instituto de Estudos Avançados, 19(54):101, 2005. Disponível em: <http://www.scielo.br/scielo.php?pid=S0103- 40142005000200006\&script=sci_arttext>. Acesso em: 23 jun. 2012.

6 Arthur Cézar Ferreira Reis, segundo Gaitano Antonaccio, nasceu em Manaus a 8 de janeiro de 1906. Cursou direito em Belém e no Rio de Janeiro nos anos 1920. No final dessa década, retornou para Manaus e tornou-se redator do periódico dirigido por seu pai Vicente Torres da Silva Reis, o Jornal do Comércio. Ferreira Reis foi também o primeiro presidente da SPVEA em 1953, nomeado por Getulio Vargas. Tornouse diretor do Instituto Nacional de Pesquisas da Amazônia (INPA). De perfil político extremamente conservador, foi em 27 de junho de 1964 nomeado, pelo presidente Humberto de Alencar Castelo Branco, governador do Estado do Amazonas. Faleceu em 1993 na cidade do Rio de Janeiro. 
resses das elites esclarecidas do Amazonas e da Amazônia, que desejavam solucionar as fragilidades herdadas do passado colonial extrativista. Obras publicadas nos anos 1960 - como A Amazônia e a cobiça internacional, Como governei o Amazonas, A Amazônia e a integridade do Brasil, de Arthur Cézar Reis, ${ }^{7}$ e Amazônia: natureza, homem e tempo, de Leandro Tocantins - são emblemáticas de tais objetivos. ${ }^{8}$

A leitura de A Amazônia e a cobiça internacional desvela a preocupação do autor com a problemática que envolve, de um lado, o subdesenvolvimento da Amazônia em relação ao restante do país e, de outro, as possíveis consequências desse subdesenvolvimento no tocante à manutenção da soberania do Estado brasileiro sobre o imenso território amazônico.

Ressalte-se que essa manutenção sempre teve de enfrentar a cobiça internacional sobre a região, e o capítulo "Mundo tropical e empório de matérias-primas", assim como outros, destaca esse problema. Isso fica evidente quando o autor aponta que as dificuldades históricas encontradas pelos colonizadores para explorar as riquezas naturais do imenso território amazônico foram responsáveis, em parte, pelo estado de subdesenvolvimento enfrentado pela Amazônia no presente.

Diante desse quadro, entretanto, é possível questionar como o autor, ao longo do livro' ${ }^{9}$ construiu a partir de seu nacionalismo a representação dos feitos dos portugueses, dos luso-brasileiros e dos próprios brasileiros no processo de defesa da Amazônia, como "projeção" ${ }^{10}$ da Amazônia cobiçada e

7 Entre suas dezenas de obras publicadas, destacam-se: História do Amazonas (1931); A política de Portugal no Vale Amazônico (1939); Paulistas na Amazônia e outros ensaios (1941); Síntese da história do Pará (1941); O processo histórico da economia amazonense (1944); O seringal e o seringueiro: tentativa de interpretação (1953); A Amazônia que os portugueses revelaram ao mundo (1957); A Amazônia e a cobiça internacional (1960); A Amazônia e a integridade do Brasil (1966).

8 Após ter estado à frente da SPVEA - órgão que foi produto de um contexto em que se pretendia tratar os problemas da região a partir de uma unidade denominada Amazônia Legal - e do INPA, Arthur Reis publicou A Amazônia e a cobiça internacional.

9 A primeira publicação de A Amazônia e a cobiça internacional se deu em 1960 pela Companhia Editora Nacional. As edições seguintes foram: Edinova, 1965; Record, 1968; Companhia Editora Americana, 1973; Civilização Brasileira/Suframa, 1982. A obra ganhou maior projeção e notoriedade com a crítica extremamente elogiosa pelo jornalista Barbosa Lima Sobrinho, "O publicista, o governador e a Amazônia", no Jornal do Brasil de 23 de maio de 1965. O crítico literário Silviano Santiago considera o livro uma das dez principais obras que, a partir dos anos 1960, analisaram a experiência brasileira não só em termos do entendimento de seu processo histórico, mas também em relação à compreensão da "alma de seus viventes" (Arthur Cezar F. Reis (1960): o recorrente olhar de desejo dos estrangeiros. O Brasil das Letras, Brasília, 2011. Disponível em: http://www.senado.gov.br/senado/ilb/BrasildasLetras/index.html. Acesso em: 17 nov. 2011).

100 uso, neste artigo, dos conceitos de "projeção" e de "retroprojeção" baseou-se na forma como Pedro Spindola Caldas e Henrique Modanez Sant'Anna os utilizaram para demonstrar como o conceito de 
desprotegida dos anos 1960. Isso se encontra, sobretudo, nos capítulos relativos à Amazônia no período do Brasil colonial e imperial.

A narrativa de Arthur Reis realiza-se como julgamento e, ao mesmo tempo, denúncia, haja vista que o autor sistematicamente se posiciona a favor de portugueses, luso-brasileiros e brasileiros em suas lutas contra outros povos europeus. Tal perspectiva não só indica a intenção do autor em conceber uma narrativa convincente para os contemporâneos que porventura desejem se engajar na defesa da Amazônia, como também revela a forma como ele procurou intuir uma consciência unitária sobre a diversidade dos fatos ${ }^{11}$ ligados à defesa da Amazônia. E é neste sentido que se torna relevante analisar a histórica cobiça e defesa da Amazônia entre os séculos XVII a XX na obra de Arthur Reis.

\section{A visão do território amazônico como um lugar instável para as pretensões dos portugueses e luso-brasileiros}

A análise da narrativa de Arthur Reis em A Amazônia e a cobiça internacional permite afirmar que seu modelo de explicação histórica teve como principio de argumentação a ideia de que o processo histórico ${ }^{12}$ amazônico sempre se desenvolveu sobre uma região instável para as pretensões de domínio dos colonizadores. Essa instabilidade, de um lado, provinha das dificuldades impostas pelo imenso território amazônico e sua natureza hostil e, por outro, se devia aos constantes assédios e pretensões de povos estrangeiros ao longo dos séculos. ${ }^{13}$

helenismo em Johann Gustav Droysen foi talhado a partir do interesse desse historiador em demonstrar a Macedônia como "Prússia da Antiguidade" e como os feitos dos exércitos de Felipe II da Macedônia teriam inspirado as estratégias do exército prussiano no processo de unificação da Alemanha, no século XIX. ("Fixar a onda de luz": o problema da transição das épocas históricas no conceito de helenismo em Johann Gustav Droysen. Revista de História da Historiografia, Ouro Preto, 1:94-98, 2008. Disponível em: http://www.ichs.ufop.br/rhh/index.php/revista/article/view/27. Acesso em: 23 mai. 2011). Neste sentido, procurou-se utilizar tais conceitos para demonstrar como a análise do passado em Arthur Reis projetou seu nacionalismo, ao mesmo tempo que os feitos dos portugueses na Amazônia deveriam se retroprojetar como exemplos a serem seguidos pelos brasileiros no presente.

11 BLOCH, Marc. Introdução à história. Mira-Sintra: Europa-América/LDA, 1997. p. 164.

12 Para Hayden White, as narrativas dos processos históricos são constituídas a partir do que ele denomina "gramática da análise histórica", a qual organiza as ações das instituições, entidades e agentes em determinado campo histórico (Meta-História: a imaginação histórica do século XIX. São Paulo: Edusp, 2008. p. 180.)

13 Esta análise da narrativa de Arthur Reis procurou estabelecer um diálogo profícuo com as formulações teóricas de Hayden White em Meta-história, cuja discussão lança luzes sobre os modos de elaboração de enredo, de argumentação e de implicação ideológica (aspectos presentes no que White denominou de estilo historiográfico), auxiliando o estudo do que já havíamos anteriormente definido como representações literárias presentes nos discursos nacionalistas a partir do século XIX. 
Essa abordagem ocorreu em capítulos como "Ingleses, irlandeses e holandeses tentam a primeira surtida" e "Os franceses participam da aventura", em que Arthur Reis relatou o gradativo aumento dos interesses ingleses e batavos e, posteriormente, dos franceses sobre a Amazônia.

Nesse sentido, o autor afirma que os relatos literários surgidos com a expedição de Pedro de Ursua em sua trajetória de penetração da Amazônia através do Peru ${ }^{14}$ serviram menos à ação efetiva de conquista dos espanhóis e mais aos propósitos de invasão de ingleses e holandeses na região, como se pode notar em suas próprias palavras:

Os holandeses e os ingleses é que se lançaram ao negócio, com decisão e impetuosidade. Disputando aos espanhóis o senhorio dos mares das terras americanas, combatendo-os, ademais, por motivos religiosos, aqueles dois povos dirigiram suas visitas, inicialmente, para as Antilhas. Plantaram ali os primeiros estabelecimentos, assentando os primeiros golpes no poderio espanhol e demonstrando-lhe que a concorrência a que se atiravam não se reduzia a uma operação militar, pois valia também como empreendimento mercantil em que se iriam fazer fortes e de que se beneficiariam com os despojos do império espanhol. ${ }^{15}$

Diante do exposto, cabe questionar quem foram, no plano narrativo de Reis, os heróis que apareceram para enfrentar os ingleses e batavos e consolidar o domínio sobre a Amazônia. Os espanhóis, além de não terem tido cuidado com a divulgação de notícias sobre a região, também não a defenderam da presença de ingleses e holandeses - os quais, vindos das Antilhas, instalaram-se, a partir do final do século XVI e início do XVII, nas costas venezuelanas e das Guianas, mais especificamente entre os rios Orenoco e Oiapoque, e, logo em seguida, penetraram o Amazonas. ${ }^{16}$ A resposta incide sobre os portugueses e os luso-brasileiros, que, mesmo a serviço da Espanha, defenderam o território com esforço e coragem decisivos para destruir, entre 1616 e 1648, todas as tentativas de penetração e conquista que ingleses e holandeses pretenderam realizar na Amazônia.

Essa reação se fazia em nome de Espanha. Na realidade, contudo, era um esforço do português e do luso-brasileiro. [...] A expansão ao longo do litoral Norte-Oeste fora atribuída aos portugueses e seus descendentes estavam enfrentando o perigo batava-britânico com a maior decisão [...] para impedir

14 Os relatos serviram para a escrita da história dessa expedição (a partir de várias crônicas) que, com sucesso, atingiu o Oceano Atlântico, numa viagem em que grande parte de seus integrantes foi morta, entre eles o próprio Ursua, quanto então a liderança passou a Lopo de Aguirre. Idem, p. 24.

15 REIS, op. cit., p. 24-25.

16 Idem, p. 24-25. 
a perda da Amazônia e como primeiro esforço para evitar que a cobiça internacional se fosse ceivando a região. ${ }^{17}$

Arthur Reis relata, em "Os franceses tentam a primeira surtida", o avanço desse povo sobre a região entre os rios Amazonas e Oiapoque a partir do século XVII, vindo a se concretizar efetivamente com a ascensão de Colbert na França, com a criação da Companhia das Índias Ocidentais e com a reação dos lusitanos contra eles:

[...] ante essa iniciativa francesa de conquista da costa do Macapá até o Amazonas, os portugueses e os luso-brasileiros não se mantiveram meros expectadores. Em livro que escrevi, há anos, sobre Limites e demarcações na Amazônia Brasileira. A fronteira colonial com a Guiana Francesa fiz o histórico pormenorizado de todo esforço que despenderam, esforço heróico, continuado, inteligente, objetivo e cheio de frutos, visando não só opor-se à penetração francesa como antecipar-lhe em criando bases permanentes na região, dessa modo integrando-se no império que procuravam construir solidamente na Sul-América. ${ }^{18}$

Dessa forma, por trás dessa representação heroica dos portugueses e dos luso-brasileiros, evidencia-se o objetivo em demonstrá-los como empreendedores de uma colonização com nítido aspecto renovador de um campo histórico cobiçado. Essa representação foi também notada na obra do autor A política de Portugal no Vale Amazônico e em artigo na revista carioca Vamos ler, provavelmente publicado no final dos anos 1930:

[...] A conquista da terra amazonense, seja a primeira iniciativa de Castello Branco, seja a segunda e ousada bandeira de Pedro de Teixeira, o alferes atrevido que penetrou pela selva selvagem de Quito, é narrada com fidelidade e documentação. As questõeseconômicas da colonização portuguezana Amazônia, entretanto, mereceu a primeira palavra de louvor ao livro do sr. Ferreira Reis. É nesse particular que a colonização desenvolvida pelos portuguezes na extensa bacia amazônica se destaca por sua natureza renovadora. ${ }^{19}$

Essa análise poderia expressar algum tipo de lição, já que, de acordo com Lademe Correia de Souza, Arthur Reis sempre procurou realizar uma

17 Idem, p. 28-29.

18 REIS, op. cit., p. 40- 41, grifo nosso.

19 A política de Portugal no Valle Amazônico. [1939?]. Disponível em: <http://200.208.241.123/prg_012. jsp>. Acesso em 23 maio 2008. Os artigos de jornais que constam neste artigo foram pesquisados na hemeroteca on-line Arthur Cézar Ferreira Reis, que esteve disponível para consulta até o ano de 2009. Parte dos artigos que foram utilizados não possui referências como autoria, local de publicação, meio de circulação e data de publicação. Oriundos de uma vasta coleção particular que o próprio autor reuniu em mais cinquenta anos de carreira como escritor e historiador, muitos foram recortados das páginas dos meios de circulação em que foram publicados sem a preocupação de que contivessem todas as referências. 
leitura dos documentos com o intuito de trazer ao presente as virtudes que o passado pudesse reverter ao "espírito dos homens". ${ }^{20}$

Pode-se verificar, em A Amazônia e a cobiça internacional e outras obras, que a façanha portuguesa e luso-brasileira teria muito a ensinar sobre a efetiva integração não só territorial, como também cultural, da Amazônia. Isso refletiu a mesma manifestação engendrada por portugueses e luso-brasileiros em termos de "vínculos de sangue, dos sentimentos sempre objetivando a uma mais intensa solidariedade de tipos, de classes, de ordem social" ${ }^{21}$ que concorreram para a unidade que se consubstanciou como plural em termos de aspectos físicos e produção diversificada no restante do Brasil.

Em Limites e demarcações na Amazônia brasileira (1948), Sidney da Silva Lobato apontou como o problema da miscigenação já havia sido fundamental para o avanço dos domínios luso-brasileiros em direção à Amazônia a partir do Nordeste, já que teria sido realizado a partir do heroico esforço dos indígenas (aliados) e dos portugueses que "se unem, se amalgamam, originando a mamelucada - afirmação da unidade social e primeira geração de brasileiros". ${ }^{22}$

Esse equilíbrio em relação ao elemento humano, por outro lado, foi relatado ainda por Sidney da Silva Lobato, em Aspectos da experiência portuguesa na Amazônia, como fruto da conquista espiritual e cultural provinda de uma profunda operação de entendimento e questionamentos minuciosos sobre o meio amazônico. Já Arthur Reis demonstrou que foi na Amazônia "que Portugal teria vivido a sua mais viva e curiosa experiência tropical, e nela teria instituído uma 'política de convivência harmônica' e 'um equilíbrio magnífico de grupos étnicos". ${ }^{23}$

A "criação de uma humanidade" nos trópicos, em A Amazônia e a cobiça internacional, entretanto, se deu a partir de uma perspectiva não dialética, já que o elemento indígena só foi valorizado diante da obra civilizadora da colonização. ${ }^{24}$

20 SOUZA, Lademe Correia de. Arthur Reis e a história do Amazonas: um começo em grande estilo. 2009. Dissertação (mestrado em história) - Universidade Federal do Amazonas, Manaus, 2009, p. 73.

21 REIS, Arthur Cézar Ferreira. A Amazônia e a integridade do Brasil. Brasília: Senado Federal/Conselho Editorial, 2001. p. 13.

22 LOBATO, Sidney da Silva. Estado, nação e região na obra de Arthur Cézar Ferreira Reis. Diálogos: Revista do Departamento de Historia e do Programa de Pós-Graduação em História da Universidade Estadual de Maringá, Maringá, 13(3), 2009, p. 633. Disponível em: http://www.redalyc.org/articulo.oa?id=305526879008. Acesso em: 20 mar. 2014.

23 Idem, p. 636.

24 Gilberto Freyre, ao relatar que a população de portugueses que veio para o Brasil no início da colonização não seria suficiente para a conquista de nosso território, construiu uma visão diferenciada da relação do português com o indígena. Ao contrário de uma missão superior que os lusos conseguiriam 
Assim, Arthur Reis, a partir de sua percepção sobre as fragilidades que tanto portugueses como luso-brasileiros possuíam para a manutenção de suas posições no imenso território, passou a enxergar, por um lado, o campo histórico amazônico como um lugar instável para as pretensões dos colonizadores e, por outro, como essencialmente reservado a eles ${ }^{25}$ pelo destino que a missão superior emanada do Estado português impôs em termos de planejamento e processo de miscigenação. Ambos os aspectos contribuíram com a integridade territorial e cultural da região amazônica.

A percepção sobre o campo histórico amazônico como um lugar instável também se nota em "Os ingleses sugerem a secessão", capítulo em que o autor procura enaltecer os feitos dos paraenses no tocante à defesa do território amazônico no contexto da Cabanagem.

Ao relatar as pressões impostas pela Inglaterra para que um dos líderes cabanos, Eduardo Nogueira Angelim, proclamasse a separação do Pará, o autor conta que Angelim rechaçou, com firmeza e em nome de sua lealdade ao Governo do Rio de Janeiro, em 1836, qualquer imposição dos britânicos que pudesse levar à secessão aquela província do restante do país. ${ }^{26}$

Para isso, o historiador lançou mão de uma atmosfera de suspense ao longo de todo o capítulo "Os ingleses sugerem a secessão" para valorizar as ações de Angelim na defesa do Pará e da própria Amazônia. Essas ações deveriam ser vistas como as de um autêntico herói, a despeito de toda a fragilidade de sua posição diante dos poderosos interesses de dominação dos ingleses e de seu poderio bélico, já que em momento algum teria colocado em xeque sua lealdade patriótica ao imperador.

\footnotetext{
impor sobre os gentios, para Freyre, o que estava por trás do sucesso da empresa colonizadora portuguesa era o pragmatismo que o elemento luso demonstrou em seu processo de miscigenação com o indígena como resposta à necessidade de enfrentamento tanto do clima quanto da natureza nos trópicos. (Casagrande e senzala: formação da família brasileira sob o regime da economia patriarcal. São Paulo: Global, 2006. p. 162-163.)

25 Essa afirmação de que Arthur Reis teria uma visão essencialista configurou-se como uma percepção de que ele, nos anos 1960, ainda possuía uma clara influência da velha concepção essencialista da história americana em que a América seria uma massa territorial irremediavelmente destinada a ser descoberta por Cristóvão Colombo, em nome da Espanha. Tal premissa, de acordo com O'Gorman, estaria calcada em modelos teóricos substancialistas que sempre procuraram demonstrar que "a realidade, o que se pensa, num determinado momento, que é uma coisa, uma coisa existente, é o que tem sido sempre e o que sempre será, sem remédio; algo definitivamente estruturado e feito, sem que haja possibilidade alguma de deixar de ser o que é para ser algo diferente. O ser - não a existência, veja-se bem - das coisas seria, pois, algo substancial, algo misteriosa e visceralmente alojado nas coisas, a sua própria natureza, isto é, aquilo que faz que as coisas sejam o que são. (O'GORMAN, Edmund. A invenção da América. São Paulo: Editora da Unesp, 1992. p. 62.)
}

26 REIS, op. cit., p. 50-54. 
Em Arthur Reis, as representações, tanto de certas figuras da colonização como do Brasil pós-colonial na Amazônia, visavam valorizar personagens que deveriam ser vistos como heróis, ao mesmo tempo que os estrangeiros deveriam ser vistos como vilões. Outro propósito, entretanto, foi realizar uma ressignificação dos ensinamentos dos homens que defenderam a Amazônia enquanto retroprojeção ${ }^{27}$ do passado para os contemporâneos de nosso historiador. Essas representações sempre foram recorrentes desde a primeira obra de Arthur Reis, A história do Amazonas.

Vejamos as palavras de Lademe Correia nesse sentido:

Reis constrói ao longo de sua obra os heróis e os vilões; para aqueles, palavras elogiosas e justificativas para os seus atos contra os nativos, ao passo que estes receberam o seu julgamento mais duro e condenatório. Tudo isso sempre redundando na busca por uma verdade ética que servisse aos princípios do presente e "à nova geração de sua terra". Ou seja, a história que planejou escrever tinha uma função didática, pois a busca pelo passado assumiu características de resolução de questões do futuro, sempre numa defesa aberta à colonização. À semelhança de Varnhagen, que no dizer de José Honório Rodrigues "quem o ler de fio a pavio, como aconselhava Capistrano de Abreu, verá que são inumeráveis as passagens de louvor e de compreensão até para com os erros da colonização". ${ }^{28}$

Esse contorno da história como "mestra da vida" na obra de Arthur Reis, no entanto, passou a se aprofundar nos anos 1950 e 1960, e se refletiu no fato de que a fundamentação empírica de sua obra foi gradativamente sendo "substituída por numerosas referências aos textos anteriormente publicados [...]. Nota-se também uma preocupação com o período recente da história da Amazônia, na qual determinadas práticas podem ser desaprovadas pelo autor, que para isso evoca as lições das experiências históricas mais remotas". ${ }^{29}$

Essa evocação das "lições das experiências históricas mais remotas" não seria possível sem o concurso ao que Francisco Colom Gonzáles afirma ser a importância da sequencialiadade na construção das narrativas históricas. Gonzáles entende que isso não só permite engendrar os acontecimentos históricos em um enredo, mas também organizar as referências coletivas e identidades morais normatizadoras no tempo e no espaço. A partir disso, o historiador poderia “conjugar o pronome 'nós' em diferenciados tempos his-

27 CALDAS; SANT'ANNA, op. cit., p. 98.

28 SOUZA, Lademe Correia de. Arthur Reis e a história do Amazonas: um começo em grande estilo. 2009. Dissertação (mestrado em história) - Universidade Federal do Amazonas, Manaus, 2009, p. 44-45.

29 LOBATO, op. cit., p. 635-636. 
tóricos”, já que, para Colom, “essa figuração moral é a que nos permite, eventualmente, assumir responsabilidades históricas, reclamar compensações ou privilegiar uma determinada filiação genealógica em nossas identidades." ${ }^{30}$ Mas Colom vai mais longe e afirma que essa busca de identidade no passado só é possível devido ao que Paul Ricouer afirmou ser a humanização do tempo quando este se torna passível de ser narrado ${ }^{31}$ :

As identidades adquirem seu potencial normativo no seio da história configurada como temporalidade dotada de sentido. [...] Isto ocorre porque a narração imitaria criativamente a experiência temporal viva, em vez de se limitar a reproduzi-la de forma passiva. A temporalidade translada-se para a linguagem na medida em que esta configura nossa experiência temporal, confusa e informe, para reordená-la. ${ }^{32}$

No capítulo "Portugal não cedeu ao meio nem aos concorrentes", o autor moveu certas imagens representativas dos portugueses diante do meio natural amazônico, como forma de revelar que esse contato desde cedo despertou neles um "estado de consciência e admiração sobre a terra" reveladores de uma identidade que seria precursora da identidade brasileira na Amazônia.

Colonos e autoridades locais, como metropolitanas, não demoraram em compreender a extensão da terra nova, sua importância como área ocupável e a necessidade de exercer-se, sem delongas e com muita objetividade, uma política visando ampliar incessantemente a conquista e extrair da Colônia quanto pudesse fornecer para o desenvolvimento da Nação. Nesse particular, ao exame mais rápido e mais simples que se faça, fica-se prontamente na certeza de que esse entendimento ocorreu logo..$^{33}$

A partir da perspectiva da "autoridade" do documento histórico, vislumbra-se como Arthur Reis impôs objetivamente as realizações dos portugueses na Amazônia como feitos de uma nação que deveria ser considerada precursora da nação brasileira. Tal fato é perceptível quando o autor escreve a palavra nação, com a letra " $n$ " em maiúsculo, para designar com mais ênfase Portugal e seu espírito de defesa e bravura, exemplo a ser seguido pelos brasileiros. Essa ideia de que a nação brasileira deveria se reconhecer como

30 GONZÁLES, Francisco Colom. A nação como relato: a estrutura narrativa da imaginação nacional. Revista Brasileira de Ciências Sociais, São Paulo, 2013, 28(82), p. 110. Disponível em: http://www.scielo.br/ scielo.php?pid=S0102-69092013000200007\&script=sci_arttext. Acesso em 21 mar. 2014.

31 Idem, p. 110.

32 Idem, p. 110.

33 REIS, 1982, op. cit., p. 45, grifo nosso. 
continuadora da tarefa civilizadora iniciada pela colonização portuguesa, entretanto, deve ser entendida dentro do contexto em que Arthur Reis sofreu influências das práticas historiográficas do IHGB. ${ }^{34}$

Ressalte-se que a perspectiva de acordo com a qual não deveria haver descontinuidade entre a metrópole e o novo país, que surgiu após o processo de independência para a construção de um perfil da nação brasileira ${ }^{35}$, esteve presente também no autor de A Amazônia e a cobiça internacional quando da instituição de raça e meio como pontos determinantes de suas análises. Essa perspectiva, ainda de acordo com Lademe Correia de Souza, o aproximou mais de Varnhagen do que de Capistrano de Abreu, historiador que passou a adotar novos preceitos na tentativa de ultrapassar o determinismo evolucionista muito presente nas análises historiográficas do período. ${ }^{36}$

\section{O espírito prático dos portugueses, luso-brasileiros e brasileiros e o sistema de competição internacional entre as nações}

Em A Amazônia e a cobiça internacional, vê-se que a disposição dos eventos visou concatenar os acontecimentos ${ }^{37}$ que objetivamente pudessem provar que o sucesso histórico da defesa da região relacionou-se ao fato de que os portugueses não teriam agido apenas por impulso e de forma provisória quando tiveram contato com as mais adversas situações impostas por uma natureza indomável, pelo elemento indígena e pelos estrangeiros.

Para Arthur Reis, se muitas ações dos colonizadores teriam sido respostas imediatas a um ambiente hostil, outras ações seriam fruto de "um estado de espírito consciente", de "decisões coletivas", programas, enfim, previamente estabelecidos para a efetiva conquista da região. ${ }^{38}$ Essa representação refletiu a ideia de que o espírito português teria se submetido aos ditames de condutas e deveres impostos pela missão superior de conquista, que o autor entendeu ter sido relegada pelo próprio devir histórico. Confirma essa posição, inclusive, em A Amazônia e a integridade do Brasil, em que

34 SOUZA, op. cit., p. 26.

35 Idem, p. 26.

36 Idem, p. 31.

37 Hayden White remete à existência de uma "sintaxe" para a disposição dos acontecimentos por parte dos historiadores (Op. cit., p. 182). Neste artigo, procurou-se demonstrar que Arthur Reis, em A Amazônia e a cobiça internacional, teve como princípio fundamental para a disposição dos fatos relativos à defesa da Amazônia os interesses do Estado português ou brasileiro diante das pressões da concorrência internacional pela Amazônia.

38 REIS, 2001, op. cit., p. 12. 
afirmou que Francisco I da França "não pudera ver o testamento de Adão para_aceitar a tese de que o Novo Mundo, realmente, devia ser uma realização ou façanha ibérica". 39

Essa visão é recorrente em obras como A Amazônia e a integridade do Brasil e Aspectos da experiência portuguesa na Amazônia, em que Arthur Reis sempre procurou impor, de acordo com Sidney da Silva Lobato, "a tese de que, mais do que o povo, o sujeito da domesticação do espaço amazônico foi o governo português", já que "enquanto os estrangeiros (franceses, ingleses e holandeses) eram cobiçosos, mercantis e imperialistas, o português se movia por uma 'vontade disciplinada', desenvolvendo uma ação mansa e segura" 40 .

Por outro lado, essa disposição dos acontecimentos que teve como fio condutor a ação do Estado português na região em A Amazônia e a cobiça internacional não deixou de levar em conta suas interconexões com os acontecimentos que foram guiados pelo sistema de Estados-nações em competição pelo mundo colonial e pós-colonial.

Essa organização dos acontecimentos pode ser percebida no capítulo "A navegação no Amazonas", em que o autor, ao relatar o histórico fechamento dos rios da região para a navegação internacional, desde o século $\mathrm{XVII}^{41}$, descreve os dramáticos episódios que passaram a envolver, de um lado, a manutenção desse fechamento enquanto herança dos portugueses que o Império deveria continuar a impor e, de outro, o insistente interesse dos ingleses, franceses e principalmente dos norte-americanos na abertura do Amazonas para a navegação mundial no transcurso do século XIX.

Assim, a forma como o autor dispõe os acontecimentos relativos à manutenção do fechamento do grande rio visaram objetivamente provar que o sucesso dessa empreitada esteve relacionado ao espírito prático e realista com que certos homens do Império brasileiro conduziram esse problema. Esse espírito pôde ser notado nos atos de fomento à criação de uma companhia de navegação, a do Barão de Mauá, e nas ações diplomáticas hábeis, altivas e seguras com que homens públicos corajosos como Ponte Ribeiro, Miguel Lisboa, Francisco Inácio de Carvalho, José Antônio Soares de Souza souberam, nessa conjuntura, defender o que demonstrava ser mais conveniente ao Império: impor a negação da abertura do Amazonas. ${ }^{42}$

39 Idem, p. 9.

40 LOBATO, op. cit., p. 636.

41 A gradativa abertura da navegação da bacia Amazônica se deu pela revogação dos atos proibitivos de navegação sobre o rio Madeira e o rio Tocantins, respectivamente aos anos de 1752 e 1730.

42 REIS, 1982, op. cit., p. 55-78. 
Ponte Ribeiro e Miguel Lisboa foram agentes enviados pelo governo imperial para firmarem acordos bilaterais para franqueamento da navegação do Amazonas em território brasileiro para os países amazônicos com o intuito de frearem as pretensões americanas sobre a região, entre os anos de 1852 e 1853. Francisco Inácio de Carvalho foi ministro dos Negócios Estrangeiros em Washington em 1853, incumbido de defender o Brasil contra as manobras realizadas pelos norte-americanos no tocante aos nossos interesses sobre a Amazônia. José Antônio Soares de Souza, que mais tarde viria a ser o Visconde do Uruguai, teve papel destacado como ministro dos Negócios Estrangeiros na época da campanha a favor da abertura do Amazonas realizada pelo tenente da Marinha norte-americana Matthew Fontaine Maury junto à opinião pública daquele país, entre os de 1850 e 1854 . Foi também responsável pela elaboração de documento oficial, cuidadosamente baseado na "doutrina do direito das gentes", que teve a função de fornecer argumentos sólidos para a negação por parte do Império brasileiro, em 1854, do pedido oficial feito por Mr. W. Trousdale, representante de Washington, para que o Amazonas fosse aberto à navegação mundial. ${ }^{43}$

Em algumas críticas da imprensa nos anos 1960, temos a percepção de como capítulos como "A navegação do Amazonas", entre outros, foram recepcionados dentro do espírito do autor em demonstrá-los como representações de uma Amazônia em perigo diante de um sistema de concorrência internacional:

Artur Cézar Ferreira Reis teve seu livro "A Amazônia e a Cobiça Internacional" publicado pela Edinova [...]. No trabalho, começa Artur Reis por falar na História velha que a atração que a Amazônia exerce sôbre povos de todo o mundo. [...] E passa a historiar o modo como se tornou brasileira a maior parte da região amazônica e dos esforços que políticos e diplomatas brasileiros desenvolveram no sentido de manterem essa hegemonia. ${ }^{44}$

Ainda:

Nas livrarias, a terceira edição - aumentada - de um dos livros mais importantes aparecidos no Brasil, nos últimos anos: A Amazônia e a Cobiça Internacional, de Arthur Cezar Reis, [...] Trata-se de obra em que a história e a sociologia política explicam os motivos pelos quais, ao longo de sua história, a Amazônia esteve sempre na alça de mira de potências e grupos estrangeiros. E a razão de seu sucesso - explica o autor - é que falou à consciência brasileira. ${ }^{45}$

43 Idem, p. 55-78.

44 O MUNDO amazônico. [1965?]. Disponível na Hemeroteca Arthur Reis. <http://200.208.241.123/ prg_012.jsp>. Acesso em 23 maio 2008.

45 A AMAZÔNIA e a Cobiça Internacional. [1968?]. Hemeroteca Arthur Cézar Reis. Disponível em: 
Essa concepção da forma como Arthur Reis concatenou os acontecimentos em sua narrativa histórica remete à tentativa de entendimento de como seu nacionalismo pôde se constituir como princípio informador de seu sistema de explicação histórica.

\section{O nacionalismo como princípio informador do sistema de explicação histórica de Arthur Reis}

Diante de tudo o que se analisou até aqui, pode-se afirmar que o princípio que informou o sistema de interpretação histórica de Arthur Reis - em meio à forma como dispôs os acontecimentos no processo histórico ${ }^{46}$ de cobiça da Amazônia - adveio da concepção presentista de seu nacionalismo. Essa concepção teve como princípio básico a ideia de que só aos nacionais caberia a apropriação cultural e espiritual de nossa Pátria na Amazônia.

Assim, o julgamento das ações de defesa por parte de portugueses, luso-brasileiros e brasileiros a partir do princípio acima discutido, em A Amazônia e a cobiça internacional, fez que Reis demonstrasse que a superação das dificuldades enfrentadas pela Amazônia nos anos 1960 (subdesenvolvimento e não integração ao restante do país) deveria se apoiar na forma como certos heróis, em determinados episódios históricos, dinamizaram "numa mobilização homogênea e bem coordenada" o que seriam os "valores espirituais e morais das energias latentes na terra e no homem"47 na Amazônia.

Sidney da Silva Lobato, a partir da leitura de outras obras do autor, percebeu que tais valores espirituais e morais seriam expressos pelos heroicos membros da elite política, de forma que no período colonial, por exemplo, a nação brasileira na Amazônia foi forjada "na identificação dos indígenas com os objetivos dos agentes do Estado português". ${ }^{48}$

Tais valores em Arthur Reis não foram estranhos aos de outros intelectuais da geração dos anos 1930 e 1940, os quais, segundo Angela de Castro Gomes, foram influenciados pela cultura política presente no Estado Novo, que propugnou o "espírito de uma nacionalidade" fruto de um "constructo" formado a partir da "recuperação" e "valorização" dos méritos e deméritos

<http://200.208.241.123/prg_012.jsp>. Acesso em 23 maio 2008.

46 WHITE, op. cit., p. 180.

47 SERÁFICO, José; SERÁFICO, Marcelo. A Zona Franca de Manaus e o capitalismo no Brasil. In: Estudos avançados, São Paulo, 19(54):105, 2005. Disponível em: <http://www.scielo.br/scielo.php?pid=S0103$40142005000200006 \&$ script=sci_arttext>. Acesso em: 23 maio 2011.

48 LOBATO, op. cit., p. 633. 
do passado histórico ${ }^{49}$. Esse passado é entendido como um "manancial de inspiração" revelador de tradições, costumes, língua, religião, raça, aspectos que, reunidos, forneceriam condições para a construção do que seria uma consciência nacional.

Neste contexto, de acordo com Sidney da Silva Lobato, Arthur Reis teria tido uma grande influência do chamado pensamento autoritário nacionalista, a partir das leituras que realizou dos autores dessa corrente, sobretudo quando afirmou que para Arthur Reis "a valorização da Amazônia é uma obra política 'porque empreendimento do Estado e não a cargo da iniciativa privada, o que não significa que a contribuição desta seja desprezada ou ignorada pelo poder público"”. ${ }^{50} \mathrm{E}$ ainda de acordo com Lobato, “o Estado, para aquele historiador, era o sujeito da valorização da região amazônica, o único que poderia libertá-la do 'sistema de rotina' nela dominante, das formas indígenas e rústicas de cultivo da terra e de extrativismo, signos de seu atraso". ${ }^{51}$

Assim, Arthur Reis expressou seu "espírito nacionalista" a partir do julgamento do passado colonial e no sentido de encontrar nele certas verdades que poderiam estar contidas no empreendimento civilizatório realizado pelo branco colonizador para seus contemporâneos..$^{52}$ Este fato revela, por outro lado, como a expressão de nacionalismo se manifestou no sistema de interpretação histórica de Arthur Reis como valor, como princípio que alimentou o significado das "virtudes" inscritas nos feitos heroicos dos portugueses na Amazônia.

Tanto em Arthur Reis como em outros historiadores nacionalistas, a evocação de efeitos morais e normativos do passado para o presente sempre mobilizou o que Francisco Colóm Gonzáles afirmou se manifestar nas estruturas dos relatos da imaginação nacional desde que estes passaram a possuir uma "posição central no repertório das ideologias modernas" ${ }^{53}$ e que diz respeito ao uso de recursos simbólicos que em boa medida sempre visaram "um retorno à vida de povos ancestrais ou à luta desses povos em relação à liberação política". ${ }^{54}$

49 GOMES, Angela de Castro. Cultura política e cultura histórica no Estado Novo. In: ABREU, M.; SOIHET, R.; GONTIJO, R. (orgs.). Cultura política e leituras do passado. Rio de Janeiro: Civilização Brasileira, 2007. p. 52-55.

50 LOBATO, op. cit., p. 638.

51 Idem, p. 638.

52 SOUZA, op. cit., p. 43.

53 GONZÁLES, op. cit., p. 107.

54 Idem, p. 107. 
o discurso nacionalista tende, assim, a recriar o passado coletivo como uma trajetória semeada de causas nobres, sacrifício trágico e cruel necessidade. Para isso, serve-se de artifícios culturais de natureza muito distinta: relatos literários, narrações históricas, rituais comemorativos, representações visuais etc. Todos esses dispositivos mostram sua funcionalidade quando se procede à manipulação inventiva da história com o fim de conceder à identidade nacional a aparência de uma existência ininterrupta no tempo. Estas histórias fornecem-nos a razão de quem somos como condição prévia para saber o que devemos fazer. o conjunto de relatos que definem as identidades nacionais supõe uma codificação do memorável, um sistema de fiação de significados dirigido a motivar uma autopercepção coletiva. ${ }^{55}$

Arthur Reis, em prefácio à quarta edição de A Amazônia e a cobiça internacional, revela como a atmosfera de suspense que criou para valorizar as ações dos grandes homens que defenderam com firmeza a Amazônia representou a forma encontrada pelo autor para projetar sobre o passado seu nacionalismo:

Nossa denúncia não se faz contra quem quer que seja, mas, como já dissemos nas páginas deste livro, a favor do Brasil. Não [...] estamos dispostos a bater palmas a qualquer projeto que possa conduzir à perda de soberania ou à vinculação de nossa terra, pela ação de cientistas ou homens de negócios, a interesses que não sejam os do Brasil..$^{56}$

Em artigo publicado no jornal A Notícia de junho de 1973, percebe-se, por comentário à quarta edição de A Amazônia e a cobiça internacional, como a recepção da crítica incorporou o que se pode chamar de "nacionalismo acendrado" do autor por trás da forma como concebeu seus heróis e organizou os episódios relativos ao problema da defesa histórica da região. Essa forma de organizar, segundo a crítica, teria a capacidade de sensibilizar a consciência nacional sobre os problemas da Amazônia na década de 1960: "O livro, por conter a denúncia contra a última sortida estrangeira à região, sendo assinada pelo Chefe do Executivo amazonense, provocou grande impacto". ${ }^{57}$

Ainda nos anos 1980, o nacionalismo presente na obra continuava a ecoar, e Geraldo Bezerra de Menezes assim se manifestou sobre a obra de Arthur Reis, dando destaque a A Amazônia e a cobiça internacional no jornal o Fluminense, afirmando que nele havia esmiuçado a história da Amazônia: "Três de suas obras, do painel desses estudos, figuram em minha biblioteca:

55 Idem, p. 108.

56 REIS, 1982, op. cit., p. 6.

57 AUGUSTO, Peri. Amazônia. A Notícia, Rio de Janeiro, 16 jun. 1973. Hemeroteca Arthur Cézar Reis. Disponível em: <http://200.208.241.123/prg_012.jsp>. Acesso em 23 maio 2008. 
[...] 'A Amazônia e a cobiça internacional', com várias edições, sendo a primeira de 1960, páginas de ardor insubmisso e predições que provocaram celeuma". 58

\section{A concepção do processo histórico posto em enredo a partir de uma estória heroico-romanesca}

Arthur Reis, ao realizar uma análise dos fatos relativos a ações de defesa da Amazônia, os transformou em dados passíveis de serem observados e, ao mesmo tempo, servirem à constituição de uma investigação histórica objetiva.

Essa busca por objetividade revelou, entretanto, a tentativa do historiador de selecionar e dispor os fatos que pudessem ressuscitar o passado de cobiças, ao mesmo tempo em que também deveriam expressar valores protonacionalistas ou nacionalistas. No entender do historiador, só dessa forma o presente poderia ser "iluminado" pelo passado, sobretudo em uma região historicamente esquecida pela nação brasileira.

A partir disso, Arthur Reis construiu sua narrativa como expressão da similitude do processo histórico de cobiça da Amazônia, ao diluir as diferenças que internamente definiriam a natureza das posições de classe e de valores entre os indivíduos que constituiriam os povos que a defenderam, ${ }^{59}$ de forma que sua narrativa pudesse demonstrá-los como possuindo uma unidade heroica diante da opressão e das intenções de dominação de outros povos.

Arthur Reis utilizou-se de duas categorias para inscrever no instável campo histórico amazônico o conflito acirrado entre os indivíduos que lutaram pela sua posse: em primeiro lugar, a dos defensores, que possuíram unidade heroica devido à simbiose que estabeleceram com o meio e com os tipos humanos que haviam tido contato, a partir da adequação, ainda que mínima, de seus valores espirituais e das necessidades políticas dos seus respectivos estados; em segundo, a dos invasores estrangeiros, povos não merecedores da conquista do imenso território amazônico, por não terem possuído as virtudes necessárias para tamanha empresa.

58 MENEZES, Geraldo Bezerra de. Arthur Cézar Ferreira Reis - 80 anos. O Fluminense, Niterói, 23 fev. 1986. 59 Se a representação heroica do povo francês em Michelet, como responsável pela salvação da França diante da opressão do Antigo Regime, diluiu as diferenças que poderiam existir entre homens e mulheres, jovens e velhos, ricos e pobres, dentro de uma operação que Hayden White denomina de dualista, vemos Arthur Reis utilizar recurso semelhante ao diluir as diferenças de classe que existiram entre os colonizadores, embora dentro do processo histórico amazônico (White, op. cit., p. 161-162). 
Assim, ao elaborar um enredo heroico para representar a luta dos portugueses e luso-brasileiros contra a cobiça estrangeira, Arthur Reis também diluiu as diferenças que existiam entre nobres, oficiais, soldados, clérigos de várias ordens, sertanistas, colonos, entre outros, já que todos portariam o sentido histórico de defesa dos interesses da monarquia portuguesa diante de sua luta contra os invasores estrangeiros. O mesmo ocorreria para a representação que fez da luta empreendida pelos brasileiros que, indiferentemente de serem políticos, diplomatas, militares, cientistas, homens do povo, entre outros, tiveram de enfrentar essa mesma cobiça estrangeira em relação ao território amazônico a partir de uma efetiva unidade que demonstraram possuir. Para Arthur Reis, todos estiveram de uma forma ou de outra a serviço de suas respectivas nações no processo de integração da Amazônia.

E aqui novamente deve-se conclamar as palavras de Francisco Colom González, para o entendimento de como essa representação que diluiu as diferenças entre diversos tipos sociais que estiveram a serviço da integridade da Amazônia se configurou como um passado subjetivamente construído pelo nacionalismo do autor, em forma de metáfora: “o vínculo comunitário que une os membros da nação é tão só metafórico, uma construção narrativa, e as metáforas podem ser eficazes na nossa imaginação". ${ }^{60}$

Ainda de acordo com Colom:

Sob um mesmo termo tendem a se subsumir momentos e experiências históricas nas quais os papéis jogados pelas classes sociais, as estruturas econômicas e políticas, as ideologias, a etnicidade, a religião e a violência se combinaram de forma muito diferente. [...] As falsidades e as mistificações se introduzem no processo político de sua elaboração narrativa, ou seja, na dinâmica ideológica do nacionalismo. ${ }^{61}$

\section{De acordo com Sidney da Silva Lobato, em Arthur Reis, a}

representação de "Amazônia" como um espaço de experiência histórica forjadora da unidade nacional contribui para a corroboração do ideal de uma "solidariedade patriótica" na qual estejam dissolvidas as diversidades de tipo e de classe social. Numa extensa nacionalidade, como o Brasil, a integração de domínios físicos diversos testemunharia a existência de uma comunhão de anseios e de vínculos profundos: "os êxitos que alcançamos sobre a paisagem física já constituem uma evidenciação muito positiva de que somos, realmente, uma Pátria indivisível”. ${ }^{62}$

60 GONZÁLES, op. cit., p. 108.

61 Idem, p. 108.

62 LOBATO, op. cit., p. 639-640. 
Essa unidade de interesses de diferentes tipos sociais no caso do período colonial foi, por exemplo, justificada no capítulo "Portugal não cedeu ao meio e nem aos concorrentes" de A Amazônia e a cobiça internacional, a partir do fato de que todos estiveram submetidos a um plano geral de colonização por parte do Estado português.

Essa perspectiva da adoção de um plano para uma efetiva conquista da região revela para A Amazônia e a cobiça internacional o que Sidney da Silva Lobato já havia percebido para Território do Amapá: perfil histórico, ou seja, a profunda "influência da retórica desenvolvimentista que predominou na intelectualidade brasileira nos anos de 1940, 1950”, quando afirmou que a consolidação da nação brasileira deveria ser realizada pela valorização econômica do espaço amazônico para que pudesse ser integrado ao restante do país. ${ }^{63}$

Pode-se perceber que a narrativa de Arthur Reis, que procurou expressar-se como similitude do processo histórico de cobiça da Amazônia, aspecto aprofundado pela ideia de planejamento enquanto projeção do presente que se prestaria a enredar vários atores sociais do passado que lutaram contra a cobiça estrangeira, também conteria metaforicamente, por intermédio das duas categorias definidoras dos povos em conflito pela posse da Amazônia, a representação da luta entre as "forças da virtude" e as "forças da usurpação", em uma perspectiva não dialética ${ }^{64}$, já que essas forças não se excluiriam nesse processo histórico.

O capítulo "Expedições científicas escondiam propósitos" retratou o perigo que as expedições científicas representaram, sobretudo entre os séculos XIX e XX:

Os portugueses mantiveram a Amazônia fechada aos olhares indiscretos e perigosos dos estrangeiros. [...] Não se diga que, dentro deste estilo de vida, os portugueses se mantiveram distanciados da preocupação de examinar com olhos de ver, nos inquéritos realizados por pessoal de alta qualificação científica, o que lhes coubera tão intensamente. Ao contrário, com uma objetividade muito louvável, também participaram do trabalho de pesquisa que se realizou entre os séculos XVI e XVII, nas Américas, procurando ter o conhecimento exato do que importavam os espaços sobre que exerciam seu império político. ${ }^{65}$

A partir disso, Arthur Reis demonstra, no capítulo "A pressão dos interesses universais", como as forças da usurpação deveriam ser temidas

63 LOBATO, op. cit., p. 640.

64 WHITE, op. cit., p. 161-162.

65 REIS, 1982, op. cit., p. 79. 
em seus objetivos de subtrair a Amazônia do restante do país a partir de seu isolamento e subdesenvolvimento nos anos 1960: "Há perigos rondando realmente a Amazônia? Depois do que aqui já foi registrado, poderá alguém duvidar do que pretendemos ter provado? No tocante ao passado, essas dúvidas não devem existir. No que diz respeito à atualidade, os perigos antevistos, propostos, terão algum fundamento?". ${ }^{66}$

Dessa forma, Arthur Reis postou os portugueses e brasileiros como representantes das "forças de uma virtude espiritual provinda de uma relação estreita de identificação e amor pela terra" contra os estrangeiros representantes das "forças usurpadoras", apenas preocupados em explorar as riquezas naturais e os povos amazônicos. Estes, entretanto, apesar de serem constantemente repelidos, nunca foram definitivamente derrotados em suas intenções de realizarem novas investidas sobre o território amazônico.

Essa representação das forças da virtude contra as forças da usurpação, entretanto, constituiu recorrência nas narrativas históricas sobre as nações, sobretudo quando se percebe, novamente a partir das discussões de Francisco Colom González - baseadas na taxonomia histórico-literária de Hayden White -, como os relatos nacionais costumam reproduzir dramas românticos de redenção, que em boa medida refletiram "a percepção salvífica do tempo cristão. [...] Consequentemente, os relatos nacionais costumam descrever uma trajetória escatológica ao longo da qual as nações nascem, despertam, caem, são redimidas ou assumem seu destino". ${ }^{67}$

A partir disso, veja-se, em artigo do Jornal do Brasil de 1965, como o traço heroico de sua narrativa foi percebido como romanticamente quixotesco a partir das representações que realizou dos colonizadores que enfrentaram a cobiça estrangeira sobre a Amazônia, sobretudo em obras como A Amazônia e a cobiça internacional. Essa representação também é incorporadora da personalidade do homem político Arthur Reis que, nos anos 1960, enfrentou e denunciou os interesses das potências estrangeiras sobre o território amazônico:

Arthur Cézar Ferreira Reis tem posição vitalícia na historiografia brasileira. [...] É possível que essa convivência com vários séculos da região amazônica, com o ingente sacrifício de seus povoadores, tenha gerado, no espírito de Arthur Reis, um sentimento mais vivo de zelo e de amor.

66 Ibidem, op. cit., p. 169.

67 GONZÁLES, op. cit., p. 115. 
Menos pelo posto, que ocasionalmente ocupa, do que pela sua profunda identificação com a causa do vale amazônico, Arthur Reis sente que desempenha, em face da Nação brasileira, a função de sentinela. Não faz, por isso, cálculos de sobrevivência política ou de êxito pessoal. Limita-se a cumprir a tarefa de sentinela. Que o acampamento desperte ou não desperte, reaja ou não reaja, já não é mais com ele. Mas todos ficarão com a certeza de que, no momento preciso, Arthur Reis embocou o clarim para o toque de alerta. ${ }^{68}$

\section{Artigo no Correio Brasiliense, publicado logo depois do lançamento da edição que ora escolhemos para analisar, foi também elucidativo das rela- ções que a crítica estabeleceu entre a história heroico-nacionalista presente nas páginas de A Amazônia e a cobiça internacional e seu próprio autor como uma espécie de escritor herói:}

Muitos são os chamados, poucos os escolhidos. Raros os escritores que conseguem escrever um clássico. Arthur Cezar Ferreira Reis é um deles, com A Amazônia e a Cobiça Internacional. Os leitores o entenderam, recompensando-o com demanda de sucessivas reedições. De novo, vox populi, vox Dei. O livro não apresenta tons euclideanos, mas termina acima das pretensões de Alberto Rangel e Gastão Cruis. Prefere ser factual, por isto crescendo tanto, com um realismo impressionante nada impressionista. A Amazônia e a Cobiça Internacional representa a culminação de uma pirâmide, construída laboriosamente pelo autor em sucessivas obras anteriores, basicamente históricas, espirituais e não só econômicas. Daí a final compreensão global, no melhor sentido weberiano. Também rasos os scholars com esta felicidade. "O Pacto Amazônico, visando à solução justa, é um caminho certo, no que diz respeito ao aproveitamento do meio físicohumano. Que essa participação, todavia, seja conduzida por nós, de acordo com nossos desejos, sem afetar, o exercício de nossa soberania, sem perturbar nossas características étnicas e culturais. ${ }^{69}$

Assim, pode-se dizer que o "tipo de narrativa genérica"70 posta em prática pelo enredo do autor expressou o tema da heroica tenacidade dos

68 SOBRINHO, Barbosa Lima. O publicista, o governador e a Amazônia. Jornal do Brasil, Rio de Janeiro, 25 maio 1965. Hemeroteca Arthur Cézar Reis. Disponível em: <http://200.208.241.123/prg_012.jsp>. Acesso em 23 maio 2008.

69 A HILÉIA REDESCOBERTA. Correio Brasiliense, Brasília, 18 nov. 1983.

70 Esse conceito é explicado por Stephen Bann a partir de Hayden White da seguinte forma: "o discurso histórico pode ser repartido em dois níveis de significado. Os fatos e sua explicação ou interpretação formal aparecem como a 'superfície' manifesta ou literal do discurso, enquanto a linguagem figurativa usada para caracterizar os fatos aponta para um significado estrutural profundo... Esta concepção do discurso histórico permite-nos considerar a história (no sentido de narrativa) específica como uma imagem dos eventos sobre os quais a história é contada, enquanto o tipo de narrativa genérico é considerado uma imagem sobre a qual os eventos devem ser encadeados a fim de permitir sua concatenação como elementos de uma estrutura reconhecível" (BANN, Stephen. As invenções da História: ensaios sobre a representação do passado. São Paulo: Edunesp, 1994, p. 63). 
portugueses, luso-brasileiros e brasileiros diante da defesa da Amazônia, a despeito da histórica fragilidade da soberania deles sobre a região durante o transcurso dos séculos XVII ao XX. Este tema, por sua vez, infere o que Hayden White denomina como modo romanesco de enredo e que teve a função de conferir à sua versão da história da cobiça "o estatuto da explicação mais justa sobre ela"71, de forma que pudesse ser lida por seus contemporâneos como revelando as "verdadeiras" fraquezas e debilidades que estiveram por trás da soberania lusa ou brasileira sobre a Amazônia no passado. Tais fraquezas e debilidades não deveriam se repetir em sua contemporaneidade para que não projetassem outros mais no futuro à soberania brasileira na região.

E, neste sentido, Silviano Santiago percebeu a perspectiva do passado apreendido em forma de metáfora, ao englobar A Amazônia e a cobiça internacional entre as obras importantes que, ao terem analisado a experiência brasileira,

[...] sempre serviram a nós de farol (e não de espelho, como quer uma teoria mimética apegada à relação estreita entre realidade e discurso). Com a sua ajuda e facho de luz é que temos caminhado, pois eles iluminam não só a vasta e multifacetada região em que vivemos, como também a nós, habitantes que dela somos, alertando-nos tantos para os acertos quanto os desacertos administrativos, tanto para o sentido do progresso moral quanto para o precipício dos atrasos irremediáveis. ${ }^{72}$

À guisa de conclusão, pode-se dizer que em A Amazônia e a cobiça internacional tem-se o sentido de uma história geral da cobiça sobre a Amazônia determinada pela ótica do nacionalismo denunciador de Arthur Reis. Esse nacionalismo é estruturador do sentido por trás de um processo histórico que procurou construir as ações passadas enquanto similitude da realidade do campo histórico ao qual pertenceram. Tais perspectivas meta-históricas tiveram a função de encadear uma série de fatos relacionados à histórica cobiça sobre a Amazônia, de forma a realizar um arranjo convincente deles em relação a suas intenções em criar uma obra de denúncia contra as intenções dos estrangeiros no que concerne a Amazônia nos anos 1960.

Esse arranjo exigiu do autor lançar mão de um enredo heroico-romanesco para as ações de portugueses, luso-brasileiros e brasileiros, que foi bem sucedido devido à forma como procurou valorizar em sua narrativa as superações de situações que pareciam incontornáveis no tocante à defesa do território amazônico. Essas situações, antes de serem superadas, foram

71 PESAVENTO, Sandra Jatahy. Fronteiras da ficção: diálogos da história com a literatura. In: SIMPÓsIO NACIONAL DE HISTÓRIA, 20., 1999; Florianópolis. Anais... São Paulo: Humanitas/USP: 1999, vol. 2. p. 819-829. 72 SANTIAGO, op. cit., p. 1. 
narradas a partir de uma atmosfera de suspeição e suspense no intuito de valorizar as vitórias dos defensores que deveriam ser vistos pelos homens do presente como reunidos em torno do sentimento de defesa da terra amazônica diante das manobras dos povos estrangeiros para conquista dela.

Tal atmosfera de suspeição e suspense produziu "efeitos de verdade" sobre a narração dos fatos relativos às ações de defesa, já que foi capaz de mobilizar em relação ao público leitor o imaginário patriótico voltado ao temor que os brasileiros sempre tiveram de perder a soberania sobre a Amazônia. Essa representação imaginária, enfim, sempre fez parte de nossa brasilidade cultora das maravilhas e riquezas da região.

Artigo recebido para publicação em: 02/05/2013 Artigo aprovado para publicação em: 28/04/2014 